\title{
NOVOS GÊNEROS E ESPÉCIES DE HOPLOPHORIONINI (HEMIPTERA, MEMBRACIDAE, MEMBRACINAE)
}

\author{
Antonio J. Creão-Duarte ${ }^{1}$
}

\begin{abstract}
NEW GENERA AND NEW SPECIES OF Hoplophorionini (HEMIPTERA, MEMBRACIDAE, MembracinaE). Two new genera - Potnioides gen.n. and Sakakibarella gen.n. - and five new species are proposed: Potnioides corniculatus sp.n. (Peru, Cuzco), Sakakibarella seminigra sp.n. (Costa Rica, Turrialba), S. costaricensis sp.n. (Costa Rica, Heredia), S. elongata sp.n. (Costa Rica, Alajuela) and S. maculata sp.n. (Colombia, Huila).

KEY WORDS. Hemiptera, Hoplophorionini, Membracidae, new taxa
\end{abstract}

\section{Potnioides gen.n.}

\section{Espécie-tipo. Potnioides corniculatus sp.n.}

Cabeça relativamente pequena, com a largura aproximadamente igual a dois terços da distância entre os úmeros. Pronoto anguloso acima do metopídio; carena média percurrente; processo posterior acuminado, terminando antes do ápice das tégminas. Tégminas com cinco células apicais e duas discoidais. Asas com três células apicais; veia $\mathbf{M}$ não ramificada; transversas $\mathbf{~ s - m ~ e ~} \mathbf{m}$-cu presentes; lóbulo jugal bem desenvolvido. Pernas I e II com tíbias estreitas e carenadas lateralmente. Coxas II com espinho basal. Pernas III com tíbias clavadas, fileiras I e II fundidas nos três quartos apicais e com setas cuculadas. Tarsos III reduzidos, menores que a metade do comprimento dos tarsos I e II. Abdome levemente achatado ventralmente; edeago em $U$.

Comentários. $\mathrm{O}$ número de células apicais das asas tem sido utilizado para distinguir grupos dentro de Hoplophorionini (GODING 1892, 1926; FUNKHOUSER 1951). Os que apresentam três células apicais podem formar dois grupos: 1) com veia $\mathbf{S 3 + 4}$ e $\mathbf{M 1 + 2}$ fundidas e, 2) com a veia $\mathbf{M}$ não ramificada e separada da $\mathbf{S 3 + 4}$ pela transversa s-m. Neste último grupo se enquadra o novo gênero Potnioides. As outras características são semelhantes às de Potnia Stål, 1866.

Etimologia. Derivado de Potnia, gênero com o qual tem grande semelhança morfológica.

1) Departamento de Sistemática e Ecologia, Universidade Federal da Paraiba: $58059-900$ João Pessoa, Paraíba, Brasil. 

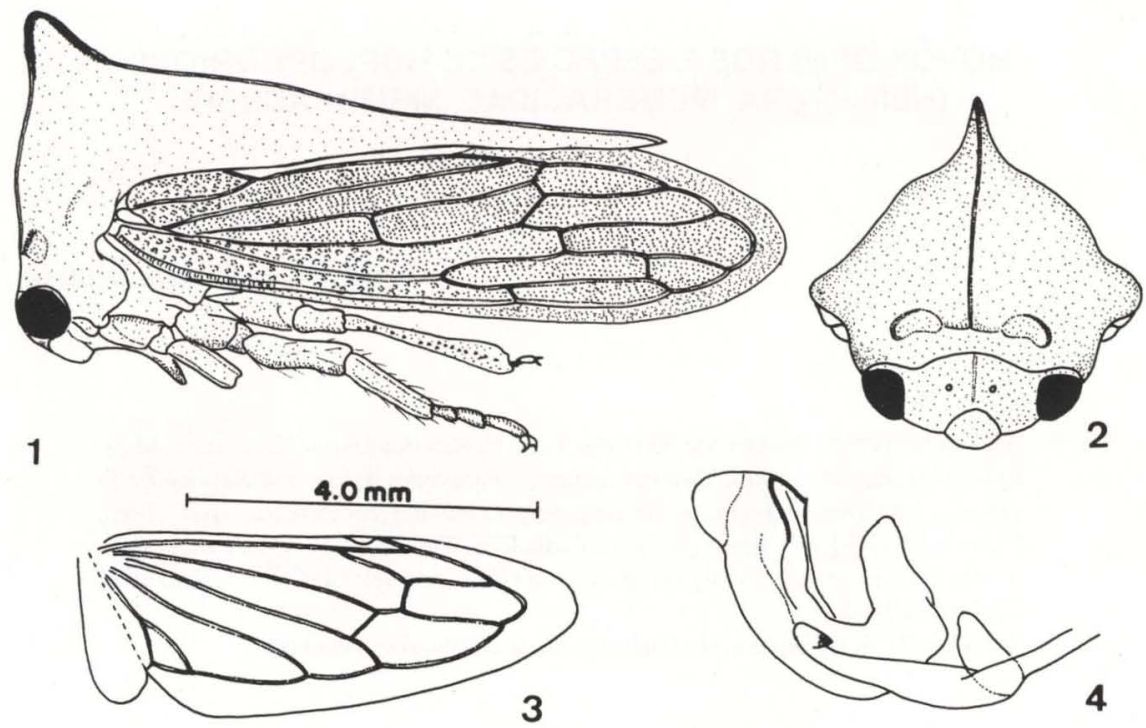

Figs 1-4. Potnioides corniculatus sp.n., holótipo macho. (1) Lateral; (2) frontal; (3) asa; (4) genitália.

\section{Potnioides corniculatus sp.n.}

Figs 1-4

Diagnose. Pronoto projetado anteriormente, acima do metopídio, em um processo curto e subcônico; processo posterior atingindo o ápice da quinta célula apical das tégminas.

Medidas (mm). Comprimento do pronoto 7,52; comprimento total 8,55; largura da cabeça 2,44; distância entre os ângulos umerais 4,00.

Descrição. Holótipo macho. Colorido geral amarelado. Cabeça subtriangular, com carena média longitudinal evidente. Olhos globulares. Ocelos ligeiramente aproximados entre si que dos olhos, situados logo acima da linha imaginária que passa pelo centro dos olhos. Pós-clípeo arredondado, mais ou menos globoso. Lóbulos suprantenais laminares, projetados para fora.

Pronoto grosseiramente pontuado, sem carenas laterais. Carena mediana escurecida ao longo do processo anterior; processo anterior curto, subcônico, situado acima do metopídio, dirigido para frente e para cima, distintamente amarelo-creme. Ângulos umerais levemente salientes. Processo posterior acuminado, com a extremidade alcançando o ápice da quinta célula apical das tégminas.

Tórax e pernas castanho-amarelados.

Tégminas ligeiramente escurecidas, com veias castanho-amareladas, bem definidas; pontuadas na metade proximal da margem costal e na base do clavo; cinco células apicais e duas discoidais.

Asas hialinas com veias bem definidas; três células apicais. 
Abdome amarelado; pigóforo com lóbulos laterais bem definidos. Edeago em U, ligeiramente expandido na margem lateral interna, perto do ápice.

Fêmea. Desconhecida.

Material examinado. Holótipo macho. PerU: Dept. Cuzco/Santa Isabel, 10.XI.1952, Felix L. Waytkowski leg., North Carolina State University-NCSU.

Comentários. O processo pronotal anterior curto, voltado para frente e de coloração amarelo-creme permite a identificação da espécie.

\section{Sakakibarella gen.n.}

\section{Espécie-tipo: Sakakibarella seminigra sp.n.}

Cabeça pequena, com a largura aproximadamente igual à metade da distância entre os ângulos umerais, quadrangular, duas vezes e meia mais larga que longa. Olhos globulares. Ocelos equidistantes entre si e dos olhos, situados sobre a linha imaginária que passa pelo centro dos olhos. Pós-clípeo com intumescências laterais, defletido no terço basal e delimitado por uma discreta carena transversal. Lóbulos suprantenais projetados para fora. Placas maxilares bem desenvolvidas e projetadas lateralmente alcançando a base das coxas I.

Pronoto grosseiramente pontuado, sem carenas laterais; anguloso anteriormente, acima do metopídio, ou com processo anterior distinto, bem desenvolvido. Metopídio convexo; pré-metopídio projetado para frente e encobrindo a base da cabeça. Carena mediana percurrente. Ấngulos umerais não projetados. Processo posterior acuminado, terminando pouco além do ápice do clavo.

Pernas pilosas. Coxas II com espinho basal. Tíbias I e II carenadas lateralmente. Tarsos I e II com quase dois terços do comprimento das tíbias. Tíbias III clavadas, sem setas cuculadas nas fileiras I e II. Tarsos III menores que a metade do comprimento dos tarsos I e II.

Tégminas pontuadas na metade proximal da margem costal e na base do clavo; veias bem definidas; cinco células apicais e duas discoidais.

Asas hialinas com veias bem definidas; quatro células apicais; veia $\mathbf{M}$ ramificada; tranversas $\mathbf{s - m}$ e $\mathbf{m}$-cu presentes.

Abdome achatado ventralmente. Macho com edeago em U; placa lateral do pigóforo bem definida.

Comentários. No aspecto geral, tem certa semelhança com Potnia Stål. Difere entretanto, pela cabeça pequena e placas maxilares projetadas lateralmente.

Etimologia. Em homenagem ao Dr. Albino M. Sakakibara, do Departamento de Zoologia, Universidade Federal do Paraná.

\section{Sakakibarella seminigra sp.n.}

Figs 5-9

Diagnose. Cabeça, parte anterior do pronoto e metade basal das tégminas, enegrecidas; margens látero-inferiores do vértice protuberantes. Pós-clípeo profundamente deprimido na base, não visível de frente. 


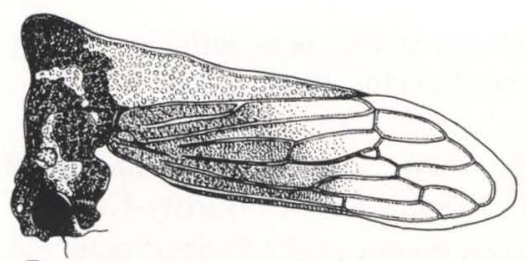

5

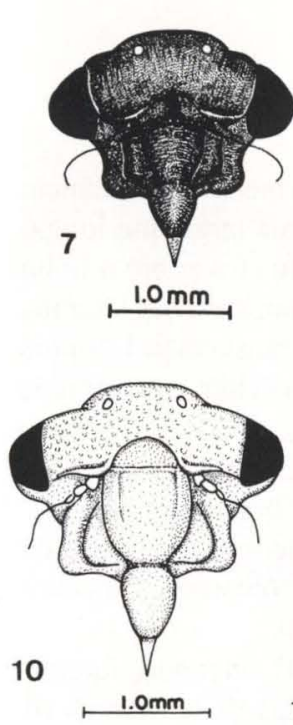

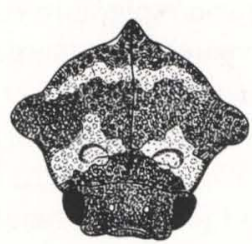

6

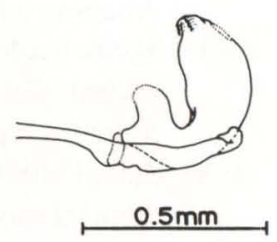

9
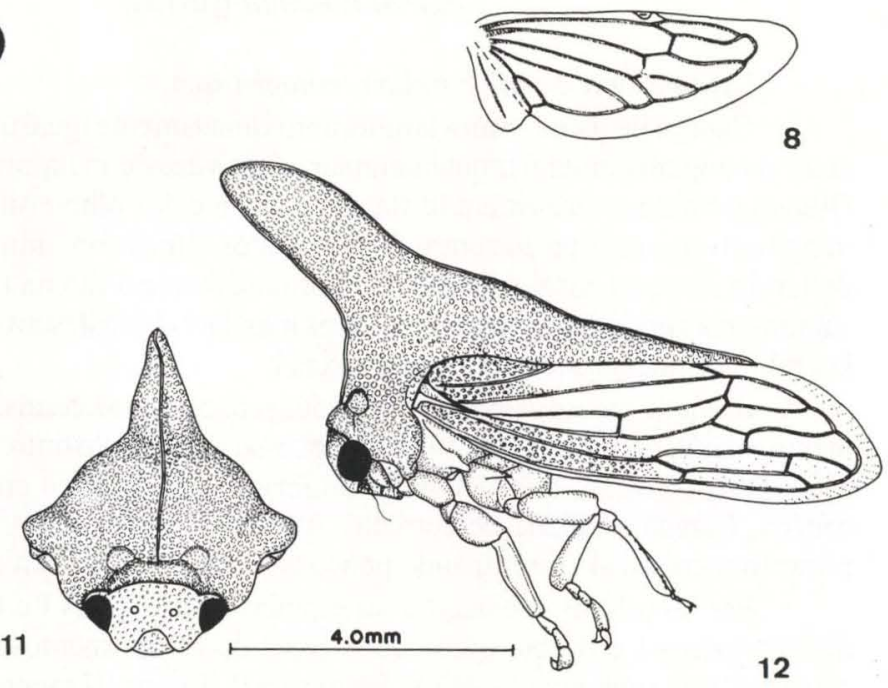

Figs 5-12. (5-9) Sakakibarella seminigra sp.n., holótipo macho. (5) lateral; (6) frontal; (7) inferior; (8) asa; (9) genitália. (10-12) Sakakibarella elongata sp.n., holótipo fêmea. (10) Inferior; (11) frontal; (12) lateral.

Medidas (mm). Comprimento do pronoto 5,00; comprimento total 6,83; largura da cabeça 1,83; distância entre os ângulos umerais 3,33.

Descrição. Holótipo macho. Colorido geral acastanhado, sendo mais escurecido na cabeça, parte anterior do pronoto incluindo o processo anterior e metade basal das tégminas; estas esfumaçadas distalmente; parte inferior do tórax e coxas, castanho-escuras; abdome preto. Cabeça pequena, com as margens látero-inferiores do vértice distintamente protuberantes. Pós-clípeo profundamente deprimido na base, não visível de frente, com duas intumescências laterais.

Pronoto grosseiramente pontuado, processo anterior muito curto, arredondado. Processo posterior acuminado, relativamente curto, terminando junto com o ápice do clavo.

Tégminas com veias bem definidas.

Edeago intumescido.

Fêmea. Desconhecida. 
Material examinado. Holótipo macho. CosTA RICA: Turrialba (1500m), VIII.1981, V.O. Becker leg., Coleção de Entomologia Pe. J.S. Moure, Departamento de Zoologia, Universidade Federal do Paraná.

Comentários. A espécie se distingue pela coloração preta da cabeça e parte anterior do pronoto.

Etimologia. Relativo à coloração acastanhada e negra do pronoto.

\section{Sakakibarella elongata sp.n.}

Figs 10-12

Diagnose. Inteiramente amarelado. Processo anterior duas vezes mais longo que largo, subespatulado apicalmente.

Medidas (mm). Comprimento do pronoto 8,00; comprimento total 7,67; largura da cabeça 2,04; distância entre os ângulos umerais 4,20.

Descrição. Holótipo fêmea. Coloração geral amarelada. Cabeça pequena, normal.

Pronoto com pontuação grosseira, com processo anterior bem desenvolvido, duas vezes mais longo que largo, subespatulado apicalmente, voltado obliquamente para frente e estendendo-se bem à frente da cabeça. Processo posterior acuminado, terminando pouco além do ápice do clavo.

Tégminas com veias bem distintas.

Macho. Desconhecido.

Material examinado. Holótipo fềmea. CosTA RiCA: Alajuela/Carrizzal (1.800m), 27.II.1988, G. Barrantes leg., Coleção da University of Connecticut. Parátipo fêmea, sem etiqueta, North Carolina State University.

Comentários. Esta espécie se distingue das outras pelo colorido geral amarelo, porte maior e pelo processo anterior bem desenvolvido.

\section{Sakakibarella costaricensis sp.n.}

Figs 13-16

Diagnose. Cabeça pequena, com as margens látero-inferiores do vértice normais. Metopídio com mancha castanho-escura. Processo anterior curto, lateralmente comprimido.

Medidas (mm). Comprimento do pronoto 5,67; comprimento total 8,17; largura da cabeça 1,92; distância entre os ângulos umerais 3,80 .

Descrição. Holótipo macho. Coloração geral castanho-escura; cabeça e metopídio logo acima da cabeça, enegrecidos; parte inferior do tórax e coxas, castanho-escuras; abdome preto. Cabeça pequena, com as margens látero-inferiores do vértice normais.

Pronoto grosseiramente pontuado, com processo anterior curto, comprimido lateralmente, voltado obliquamente para frente, estendendo-se ligeiramente à frente da cabeça. Processo posterior acuminado, curto, terminando junto com o ápice do clavo. 
Tégminas com veias bem distintas.

Edeago intumescido.

Fêmea. Desconhecida.

Material examinado. Holótipo macho. CosTA RICA. Heredia/Rio Ciruela/Porrosati (1.900m), V.1990, A. Fernandez leg., coleção do Instituto Nacional de Biodiversidad - INBIO, Costa Rica.

Comentários. Esta espécie é muito próxima de $S$. seminigra, diferindo principalmente na forma da cabeça que não apresenta as margens látero-inferiores do vértice protuberantes.
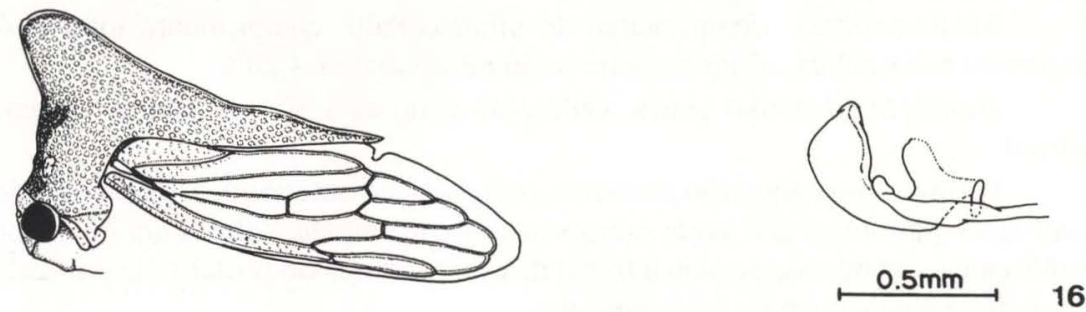

13

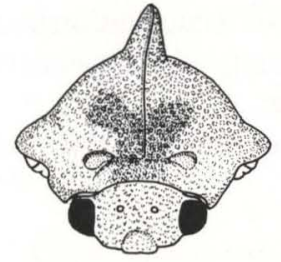

14

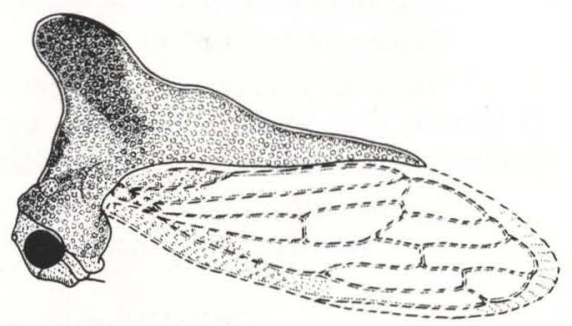

17
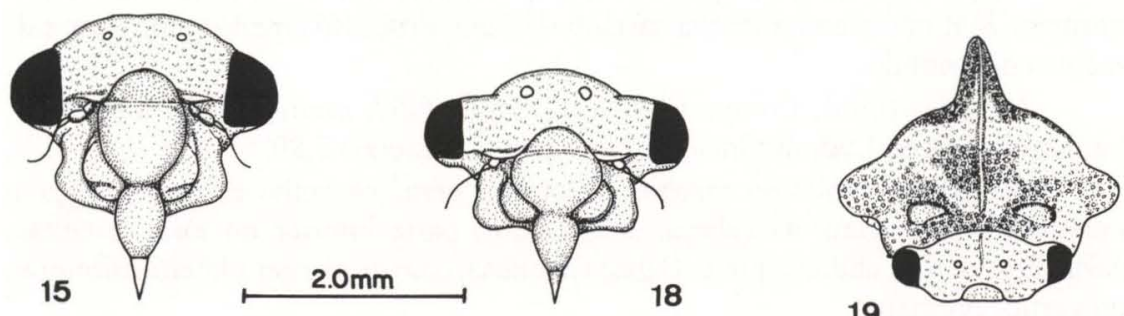

$18 \quad 19$

Figs 13-19. (13-16) Sakakibarella costaricensis sp.n., holótipo macho. (13) Lateral; (14) frontal; (15) inferior; (16) genitália. (17-19) Sakakibarella sinuosa sp.n., holótipo fêmea. (17) Lateral; (18) inferior; (19) frontal. 


\section{Sakakibarella sinuosa sp.n.}

Figs 17-19

Diagnose. Cabeça bem mais larga que longa. Pronoto com o dorso sinuoso. Processo anterior curto.

Medidas (mm). Comprimento do pronoto 4,67; comprimento total 6,17; largura da cabeça 1,93; distância entre os ângulos umerais 3,08.

Descrição. Holótipo fêmea. Coloração geral acastanhada; cabeça, metopídio, processo anterior com faixas estendendo-se até os ângulos umerais, parte inferior do tórax e abdome, castanho-avermelhados. Cabeça muito mais larga que longa, margens látero-inferiores do vértice normais.

Pronoto com processo anterior curto, obliquamente voltado para frente e projetado levemente à frente da cabeça. Linha de contorno dorsal sinuoso. Processo posterior acuminado, terminando pouco além do ápice do clavo.

Tégminas com veias bem definidas.

Pernas pilosas.

Macho. Desconhecido.

Material examinado. Holótipo fêma. ColôMBIA: Huila/San Augustin $(1.500 \mathrm{~m}), 8 . X I .1971$, M. Cooper leg., (Tégmina e asa, do lado esquerdo, faltando), The Natural History Museum, Londres.

Comentários. Esta espécie é muito parecida com $S$. costaricensis diferindo na forma da cabeça que é muito mais larga que longa, e pelo dorso nitidamente sinuoso.

\section{REFERÊNCIAS BIBLIOGRÁFICAS}

GoDING, F.W. 1892. A synopsis of the subfamilies and genera of the Membracidae of North America. Trans. Amer. Entomol. Soc. 19: 253-262.

- 1926. Classification of the Membracidae of America. Jour. N.Y. Entomol. Soc. 34: 295-317.

FUNKHOUSER, W.D. 1951. Homoptera. Fam. Membracidae. In: P. WYTSMAN (Ed.).

Genera Insectorum. 208. Bruxelles, Louis Desmet-Verteneuil, 383p.

STÅL, C. 1866. Analecta hemipterologica. Berliner ent. Ztschr. 10: 381-394.

Recebido em 16.VIII.1996; aceito em 22.VII.1997. 